\title{
REVIEW
}

\section{Monitoring cardiac function in intensive care}

\section{S M Tibby, I A Murdoch}

Arch Dis Child 2003;88:46-52

Systolic cardiac function results from the interaction of four interdependent factors: heart rate, preload, contractility, and afterload. Heart rate can be quantified easily at the bedside, while preload estimation has traditionally relied on invasive pressure measurements, both central venous and pulmonary artery wedge. These have significant clinical limitations; however, adult literature has highlighted the superiority of several novel preload measures. Measurement of contractility and afterload is difficult; thus in clinical practice the bedside assessment of cardiac function is represented by cardiac output. A variety of techniques are now available for cardiac output measurement in the paediatric patient. This review summarises cardiac function and cardiac output measurement in terms of methodology, interpretation, and their contribution to the concepts of oxygen delivery and consumption in the critically ill child.

See end of article for authors' affiliations

. Paediatric Intensive Care, Guy's Hospital, London SEl 9RT, UK;

Shane.Tibby@ gstt.sthames.nhs.uk

Accepted 3 September 2002

\begin{abstract}
A ccurate assessment and monitoring of cardiac function in the intensive care unit (ICU) is essential, as the heart is one of the commonest organs to fail during critical illness. ${ }^{1}{ }^{2}$ In addition, other failing organs as well as therapies supporting these organs may have an indirect effect on myocardial performance. ${ }^{3}{ }^{4}$ The need to monitor cardiac function is underlined by the fact that a low flow state carries a higher mortality in certain diseases. ${ }^{56}$ As flow cannot be consistently estimated clinically, ${ }^{7}$ we often titrate therapies to maintain an acceptable blood pressure. While maintenance of an adequate perfusion pressure to organs is vital, it can be seen from table 1 and equation 1 that blood pressure is affected by cardiac output (CO) and systemic vascular resistance (SVR).
\end{abstract}

Mean blood pressure $\approx$ cardiac output $\times$ systemic vascular resistance

Thus a low blood pressure may be secondary to a low CO, low SVR, or both. Conversely a normal blood pressure can exist in the face of decreased CO if SVR is high. A low CO may occur for many reasons including inadequate vascular volume, excessive afterload, poor contractility, myocardial restriction, diastolic dysfunction, valvular stenosis/insufficiency, or an arrhythmia. Any of these abnormalities may coexist, and can fluctuate during the course of an illness, meaning that an appropriate therapy at one point in time can become inappropriate as the patient's clinical state alters. ${ }^{6}$ Thus the role of cardiac monitoring encompasses assessment of the initial haemodynamic state, judging response to therapy, and ongoing evaluation of change in haemodynamic state with disease progression.

In this review we will discuss various aspects affecting cardiac function and its closely related parameter $\mathrm{CO}$, outline modalities for $\mathrm{CO}$ measurement, examine some of the qualitative parameters pertaining to the adequacy of $\mathrm{CO}$, and finally attempt to integrate these parameters into the wider spectrum of monitoring metabolic "wellbeing" in the critically ill child, with particular reference to the oxygen delivery/ consumption balance.

\section{WHAT IS CARDIAC FUNCTION?}

Cardiac systolic function is the net product of four interrelated variables: heart rate, preload, contractility, and afterload. ${ }^{8}$ Quantification of these individual components of cardiac function in the clinical setting poses two major problems. First, the methods used require either invasive (usually ventricular) pressure and volume measurements, or highly specialised echocardiographic techniques. The invasive methods usually entail manipulation of one of the elements while measuring another (for example, altering preload to calculate contractility from either end systolic elastance $^{9}$ or preload recruitable stroke work ${ }^{10}$ ), which is impractical in the critically ill patient. Second, all components display a degree of interdependence, thus an apparent deficiency in one element of cardiac function may actually be secondary to a problem with one or more of the other facets. A simple example involves a tachyarrhythmia (heart rate) reducing the time for diastolic ventricular filling (preload). Here preload restoration involves treating the arrhythmia, rather than volume replacement.

Early work aimed at quantifying myocardial performance centred on systolic function, however it is now known that diastolic mechanics are also crucial. ${ }^{11}$ Diastolic function encompasses both the rate and degree of ventricular relaxation, containing active and passive components. ${ }^{12}$ Like systolic performance, this parameter is not easily interpreted at the bedside..$^{13} 14$

The interplay of heart rate, preload, contractility, and afterload results in CO, which is defined as the volume of blood ejected by the heart per minute. As such, CO represents the clinical manifestation of cardiac function, which can be measured at the bedside. In children $\mathrm{CO}$ is often

Abbreviations: $\mathrm{CO}$, cardiac output; ICU, intensive care unit; SVR, systemic vascular resistance 
Table 1 Common measured and calculated haemodynamic variables ${ }^{20} 76$

\begin{tabular}{|c|c|c|c|}
\hline Parameter & Formula & Normal range & Units \\
\hline Cardiac index & $\mathrm{Cl}=\mathrm{CO} /$ body surface area & $3.5-5.5$ & $\mathrm{I} / \mathrm{min} / \mathrm{m}^{2}$ \\
\hline Stroke index & $\mathrm{SI}=\mathrm{Cl} /$ heart rate & $30-60$ & $\mathrm{ml} / \mathrm{m}^{2}$ \\
\hline Arterial oxygen content & $\mathrm{CaO}_{2}=\left(1.34 \times \mathrm{Hgb} \times \mathrm{SaO}_{2}\right)+\left(\mathrm{PaO}_{2} \times 0.03\right)$ & & $\mathrm{ml} / \mathrm{l}$ \\
\hline Oxygen delivery & $\mathrm{DO}_{2}=\mathrm{Cl} \times \mathrm{CaO}_{2}$ & $570-670$ & $\mathrm{ml} / \mathrm{min} / \mathrm{m}^{2}$ \\
\hline Fick principle & $\mathrm{Cl}=\mathrm{VO}_{2} /\left(\mathrm{CaO}_{2}-\mathrm{CvO}_{2}\right)$ & $160-180$ (infant $\mathrm{VO}_{2}$ ) & $\mathrm{ml} / \mathrm{min} / \mathrm{m}^{2}$ \\
\hline & & $100-130$ (child $\mathrm{VO}_{2}$ ) & $\mathrm{ml} / \mathrm{min} / \mathrm{m}^{2}$ \\
\hline Oxygen extraction ratio* & $\mathrm{OER}=\left(\mathrm{SaO}_{2}-\mathrm{SvO}_{2}\right) / \mathrm{SaO}_{2}$ & $0.24-0.28$ & \\
\hline Oxygen excess factor* & $\Omega=\mathrm{SaO}_{2} /\left(\mathrm{SaO}_{2}-\mathrm{SvO}_{2}\right)$ & $3.6-4.2$ & \\
\hline Systemic vascular resistance index & SVRI $=79.9 \times($ MAP $-C V P) / C I$ & $800-1600$ & dyn-s $/ \mathrm{cm}^{5} / \mathrm{m}^{2}$ \\
\hline Left ventricular stroke work index & $L V S W I=S I \times M A P \times 0.0136$ & 50-62 (adult) & $\mathrm{g}-\mathrm{m} / \mathrm{m}^{2}$ \\
\hline
\end{tabular}

$\mathrm{CO}$, cardiac output; $\mathrm{Cl}$, cardiac index; $\mathrm{CVP}$, central venous pressure $(\mathrm{mmHg}) ; \mathrm{CaO}_{2}$, arterial oxygen content; $\mathrm{CvO}_{2}$, mixed venous oxygen content; $\mathrm{DO}_{2}$, oxygen delivery; Hgb, haemoglobin concentration (g/l); LVSWI, left ventricular stroke work index; MAP, mean arterial pressure (mmHg); OER, oxygen extraction ratio; $\mathrm{PaO}_{2}$, partial pressure of dissolved oxygen; $\mathrm{SaO}_{2}$, arterial oxygen saturation; $\mathrm{SvO}_{2}$, mixed venous oxygen saturation; $\mathrm{SI}$, stroke index; SVRI, systemic vascular resistance index; $\mathrm{VO}_{2}$, oxygen consumption; $\Omega$, oxygen excess factor.

* The equations given for OER and $\Omega$ are only valid if the contribution from dissolved oxygen is minimal. If this is not the case, oxygen content $\left(\mathrm{CaO}_{2}\right.$ $\left.\mathrm{CvO}_{2}\right)$ must be substituted for saturation $\left(\mathrm{SaO}_{2}, \mathrm{SvO}_{2}\right)$.

indexed to body surface area, known as cardiac index, with the same set of "normal" values applying $\left(3.5-5.5 \mathrm{l} / \mathrm{min} / \mathrm{m}^{2}\right)$ regardless of patient age and size. However it must be appreciated that the term "normal" may be misleading (see Interpretation of $\mathrm{CO}$, below); for example, a low $\mathrm{CO}$ is not uncommon following cardiac surgery ${ }^{15}$ and may not hold the same poor prognosis as when found in the setting of sepsis. ${ }^{56}$

\section{WHEN SHOULD CO BE MEASURED?}

Cardiac output measurement is not mandatory for every child admitted to the ICU. The decision to measure CO represents a balance between the risks involved with the measurement process, and the potential benefits gained from the additional haemodynamic information. The latter point requires a thorough understanding of both the modality used and the basic principles of cardiovascular physiology; if both of these criteria are not met there is potential for iatrogenic harm to the patient. For example, a technique with poor repeatability (a high coefficient of variation) may produce two consecutive readings with differing results without a true change in CO. This may falsely be interpreted as a fall in CO, resulting in an unnecessary intervention or therapy. If the clinician understands the modality's limitations he/she may take the necessary steps to minimise variability (such as measuring during steady state conditions, averaging several consecutive measurements, etc) and is better placed to judge when a difference between two readings represents a true change in CO.

The importance of "understanding the process" of $\mathrm{CO}$ measurement has been highlighted in two large studies examining adult ICU physicians' knowledge of the pulmonary artery catheter, which has been the commonest method of CO measurement for nearly 30 years. ${ }^{16}{ }^{17}$ Nearly half of the respondents could not correctly identify a wedge pressure (a measure of preload, and thus a guide to fluid management), over half could not recognise when the catheter was incorrectly sited in a systemic artery, and many could not quantify the relative influence of individual components of oxygen delivery. However, physicians who scored well tended to be senior, used the catheter more frequently, had responsibility for supervising catheter insertion, and worked in hospitals with medical school affiliations. The message from these studies, that adequate training and supervision are vital prerequisites for CO measurement, is likely to apply to paediatric practice, regardless of the method used to measure CO.

Thompson has suggested several areas where paediatric CO measurement may be indicated: congenital and acquired heart disease, shock states, multiple organ failure, cardiopulmonary interactions during mechanical ventilation, and clinical research which leads to a greater understanding of a disease process. ${ }^{18}$ We would add assessment of selected new therapies (for example, a novel inotrope) to this list.

\section{CHOICE OF TECHNIQUE FOR CO MONITORING}

Shephard et al have identified eight desirable characteristics for any monitoring technique: accuracy, reproducibility, rapid response time, operator independence, ease of application, no morbidity, continuous use, and cost effectiveness. ${ }^{19}$ Unfortunately, no such technique exists for $\mathrm{CO}$ measurement in either paediatric or adult practice; thus the choice of method may vary depending on the patient and the clinical situation. A detailed description of all techniques available for CO measurement is beyond the scope of this article and is available elsewhere..$^{20-24}$ Instead we will broadly outline the measurement principles below, while specific techniques are summarised in table 2 .

The main principles of $\mathrm{CO}$ measurement include the Fick principle, indicator dilution, Doppler ultrasound, bioimpedance, and arterial pulse contour analysis.

\section{The Fick principle}

The Fick principle for flow measurement is now over a century old, and relates $\mathrm{CO}$ to oxygen consumption and the arteriovenous oxygen content difference (table 1). The equation may also be modified using $\mathrm{CO}_{2}$ production and content, which has been adapted to provide non-invasive estimation. ${ }^{25}$ Traditional techniques for measuring oxygen consumption, namely the Douglas bag, spirometry, and more recently mass spectrometry, have limited the clinical utility of this technique in the ICU. However, with the advent of portable metabolic monitors adapted for paediatric use, this technique is now possible in children and infants. ${ }^{26}{ }^{27}$

\section{Dilution techniques}

Dilution techniques have existed for many years. ${ }^{28}$ Briefly, blood flow can be calculated following a central venous injection of an indicator by measuring the change in indicator concentration over time at a point downstream of the injection, provided that a series of conditions are met. These include complete mixing of the indicator and blood, no loss of indicator between injection and measurement, no anatomical shunt, and minimal valve regurgitation. The earliest indicator used was dye, and later temperature with the introduction of the pulmonary artery catheter in the early 1970s, followed by transpulmonary thermodilution in the $1990 \mathrm{~s} .{ }^{29}$ A new indicator, lithium chloride, has recently been described in adults and children. ${ }^{30} 31$

\section{Doppler ultrasound}

Cardiac output may be calculated using Doppler ultrasound in conjunction with 2D echocardiography. Blood velocity is calculated from the frequency shift of reflected ultrasound waves using the Doppler principle. ${ }^{22} 23$ This is usually measured in the aorta, from either the transthoracic or transoesophageal 


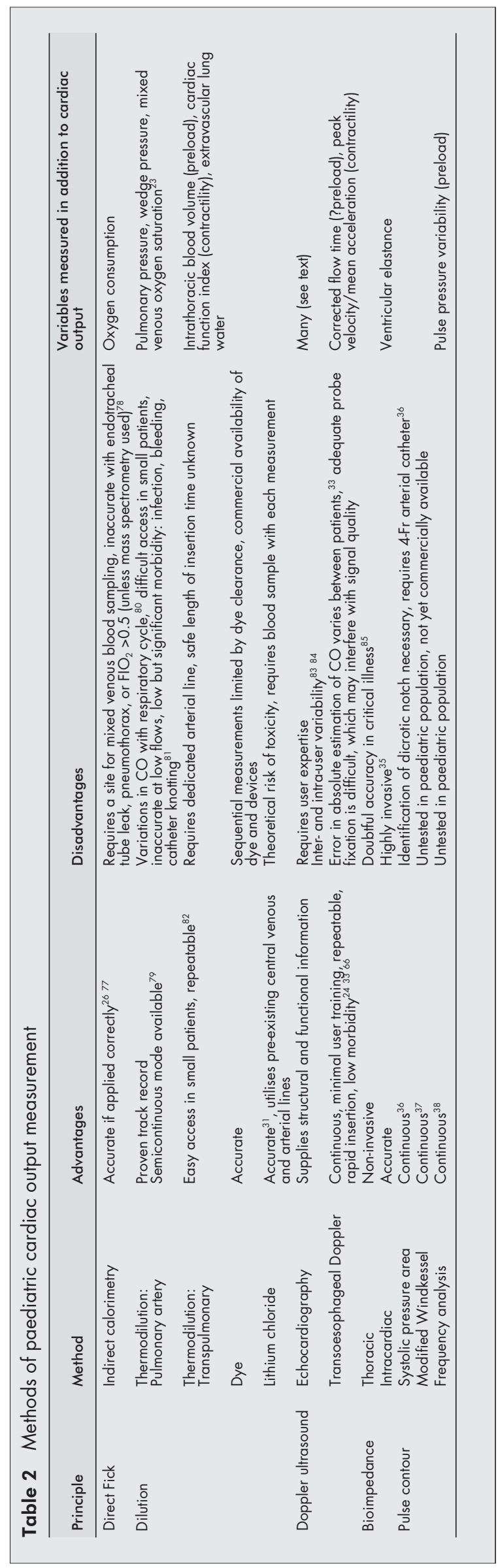

approach (the latter being continuous). Here the velocity-time integral is known as stroke distance, which is the distance that a column of blood will travel along the aorta in one cardiac cycle. Stroke distance can be converted to stroke volume, and hence $\mathrm{CO}$ with 2D echocardiographic measurement of outflow tract dimension. However, a nomogram now exists for estimation of CO using transoesophageal Doppler ultrasonography alone, making this technique available to ICU practitioners who do not possess echocardiography training. The assumptions inherent in the nomogram produce a small error in CO unique to each patient, although changes in $\mathrm{CO}$ are tracked accurately. 32

Echocardiography however, in the hands of an appropriately trained clinician, supplies a vast amount of functional and morphological information in addition to CO measurement, including indices of diastolic dysfunction, regional wall abnormalities, valve regurgitation, pericardial effusion, chamber dilatation, and cardiac chamber interdependence (see also the following sections: What is cardiac function?, Preload, Contractility, and Afterload). ${ }^{33}$

\section{Bioimpedance}

Thoracic bioimpedance involves the placement of voltage sensing and current transmitting electrodes on the chest, which may be regarded as a conductor whose impedance is altered by changes in blood volume and velocity with each heartbeat. Stoke volume is calculated from an equation involving baseline and maximum rate of change in impedance, ventricular ejection time, and thoracic segment length. ${ }^{22}$ The accuracy of this technique is dramatically increased (along with its invasiveness) when the conductance catheter is placed directly in the left ventricle, rather than on the chest wall..$^{35}$

\section{Arterial pulse contour analysis}

Erlanger suggested a relation between $\mathrm{CO}$ and arterial pulse contour nearly a century ago. This led to the development of a number of analytical methods quantifying change in stroke volume based on characteristics of the arterial pulse pressure wave. The advent of fast computer microprocessors has meant that several of these methods are now commercially available, providing stroke volume and $\mathrm{CO}$ on a continuous basis. ${ }^{36-38}$ However, all must be calibrated using another method of CO measurement.

\section{INTERPRETATION OF CO}

As discussed earlier, it is imperative that the clinician has a thorough understanding of the limitations, accuracy, and risks of the method used to determine CO, to avoid generation of spurious data. Perhaps the greater challenge however lies in "understanding the number" once it is generated. We suggest that CO should ideally be interpreted from four aspects:

(1) A quantitative element

(2) A qualitative element

(3) A temporal element

(4) As part of a global (an ideally a regional) assessment of metabolic wellbeing.

Points $1-3$ can be summarised as: the CO is " $\mathrm{x}$ " $1 / \mathrm{min}$, which is adequate/inadequate for this patient at this time. Integration of $\mathrm{CO}$ into a global metabolic assessment necessitates an appreciation of the contribution of CO to oxygen delivery, and an understanding of the balance between oxygen delivery and consumption (table 1, fig 1). From a clinical perspective, this requires the consideration of four questions:

(1) Is the delivery of oxygen adequate to meet the metabolic need of the patient, both on a global and a regional scale?

(2) Is oxygen delivery occurring with an adequate perfusion pressure? 


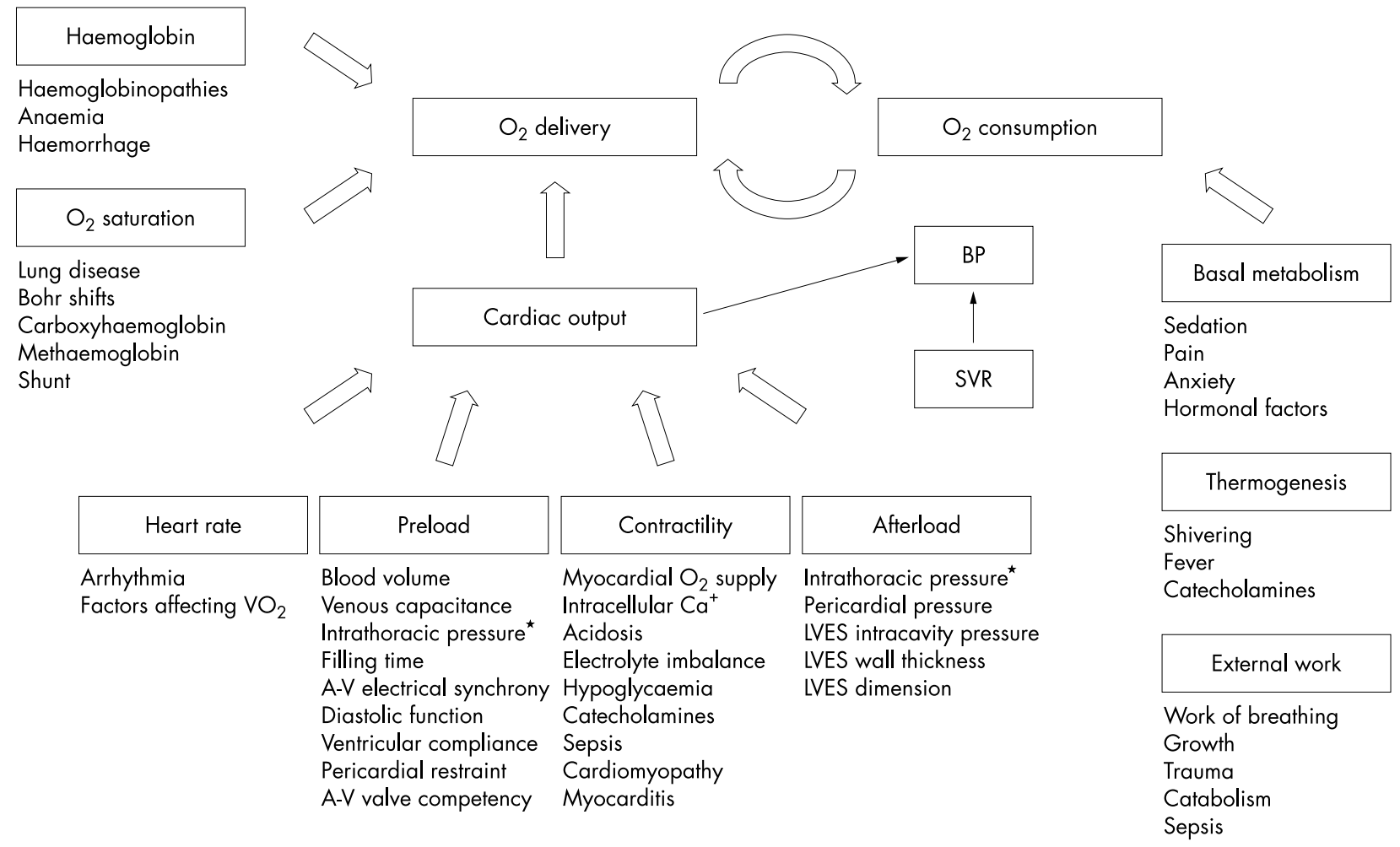

Figure 1 Factors affecting oxygen delivery and consumption. BP, systemic blood pressure; SVR, systemic vascular resistance; $\mathrm{VO}_{2}$, oxygen consumption; A-V, atrioventricular; LVES, left ventricular end systolic. ${ }^{*}$ Common intensive care scenarios augmenting intrathoracic pressure include mechanical ventilation, pneumothorax, pleural/pericardial fluid collections.

(3) Is the patient able to utilise the oxygen delivered?

(4) If the answer to any of the above is "no", why is this so?

\section{ADEQUACY OF CO AND OXYGEN DELIVERY}

A variety of clinical, laboratory, and physiological variables exist which may help to indicate adequacy of CO and/or oxygen delivery.

\section{Global indicators \\ Lactate}

With the advent of automated blood lactate analysers, interest in this parameter has seen an explosion in the last decade. Simplistically, an increased blood lactate is thought to represent anaerobic metabolism, which occurs when oxygen delivery is inadequate, or oxygen utilisation is impaired (tissue dysoxia). Recent evidence suggests that this may be an oversimplification, as other factors such as increased glycolytic flux and lactate clearance may also play a part. ${ }^{39}$ Nonetheless this parameter has prognostic value, ${ }^{40}{ }^{41}$ particularly when followed temporally, ${ }^{42}$ thus any increase in blood lactate is a cause for concern and the aetiology must be aggressively sought.

\section{Mixed venous oxygen saturation}

From the Fick principle (table 1) it can be seen that a low CO or excessive oxygen consumption can be partially compensated by an increase in the arteriovenous oxygen difference. This commonly translates into a fall in mixed venous saturation, as arterial blood is often almost fully saturated and the contribution of dissolved oxygen to total oxygen content is usually minimal. This is an early compensatory mechanism, and may precede a rise in blood lactate. Again, from the Fick equation, it can be seen that, at a constant oxygen consumption and arterial oxygen saturation, the relation between change in mixed venous saturation and CO is not linear, in other words a given decrease in mixed venous saturation may represent a comparatively larger decrease in CO (fig 2).
Mixed venous blood should ideally be taken from the pulmonary artery or the right ventricle ${ }^{43}$; however, these sites may be inaccessible in the small infant. Right atrial catheters may, in theory selectively sample desaturated coronary venous blood; however, in practice this does not seem to be the case. ${ }^{43}$ Central venous sites have been advocated, although this is subject to ongoing debate. ${ }^{44}$ The oxygen saturation of central venous blood from either the superior or inferior vena cavae

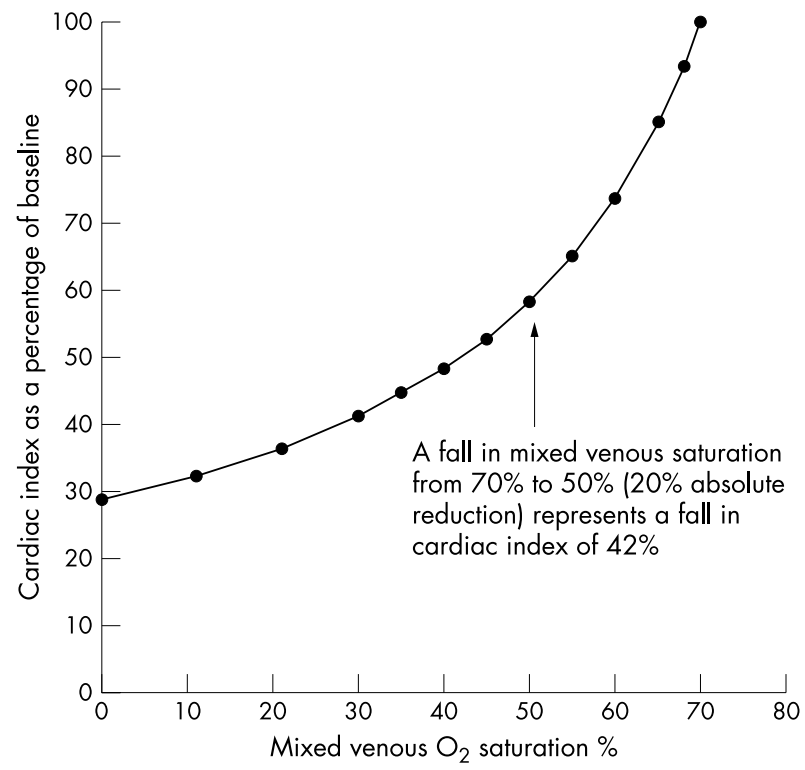

Figure 2 Relative change in cardiac index versus change in mixed venous oxygen saturation. The relation assumes the following to be constant: oxygen consumption $180 \mathrm{ml} / \mathrm{min} / \mathrm{m}^{2}$, haemoglobin concentration $120 \mathrm{~g} / \mathrm{l}$, arterial oxygen saturation $98 \%$. Baseline cardiac index is $4 \mathrm{l} / \mathrm{min} / \mathrm{m}^{2}$. 
will not be identical to true mixed venous blood, ${ }^{44}$ because of age and disease related variations in flow and oxygen consumption between the upper and lower body. ${ }^{44}{ }^{45}$ However the differences may not be great, and may be suitable for trend following. ${ }^{44}$ Venous oxygen saturation will also be partly dependent on arterial oxygen saturation, thus the arteriovenous difference or the oxygen extraction ratio are better alternatives in the face of lung pathology (table 1). The inverse of the oxygen extraction ratio is known as the oxygen excess factor, or omega ${ }^{46}$ Omega represents the ratio of oxygen delivery to consumption, and has an advantage over $\mathrm{CO}$ in that it may be calculated in the setting of an anatomical shunt. ${ }^{47}$

\section{Regional indicators}

An apparently adequate global oxygen delivery may mask significant regional abnormalities. ${ }^{48}{ }^{49}$ Unfortunately, comprehensive clinical tools assessing all aspects of regional perfusion are lacking; however, several of the common methods are detailed below.

Capillary refill and core-peripheral temperature difference Provided that it is measured correctly, capillary refill has proven useful as a marker of hypovolaemia and perhaps poor myocardial function during acute assessment and early resuscitation..$^{51}$ The significance of this parameter in ICU is less clear, and may be obscured by confounding factors such as fever, ambient temperature, and vasoactive medication use. ${ }^{52}$ In the ICU there is a surprising positive correlation with central venous pressure $(r=0.34)$, which is perhaps as much of a commentary on the limitation of central venous pressure as a marker of hypovolaemia. ${ }^{52}$ Capillary refill correlates negatively $(r=-0.46)$ with stroke volume, and the optimal predictive value for a reduced stroke volume comes from a refill time $\geqslant 6$ seconds. ${ }^{52}$ There is no correlation with systemic vascular resistance. $^{52}$ Despite these limitations, we believe capillary refill has a useful role in temporal haemodynamic monitoring. It is a quick, easy bedside test, and a dramatic change in this parameter should alert the clinician to a more detailed haemodynamic assessment of the patient. The correlation between core-peripheral temperature difference and invasive haemodynamic parameters is very poor; this parameter offers no real advantage over capillary refill..$^{52} 53$

\section{Other regional indicators}

A change in the level of consciousness in a patient with septic shock may be erroneously interpreted as secondary to "meningitis" or cerebral oedema; in reality this often represents cerebral hypoxia caused by lack of blood flow, and is, in our experience an ominous sign. Splanchnic oxygen delivery has been quantified using gastric tonometry. ${ }^{54}$ Here a semipermeable balloon is placed in the stomach, and gastric mucosal $\mathrm{CO}_{2}$ is allowed to equilibrate with the medium in the balloon. The medium may be either saline or recirculating gas, the latter method being the more accurate. ${ }^{555}$ Regional hypoperfusion or failure of oxygen utilisation are revealed by a large difference between mucosal $\mathrm{pCO}_{2}$ and arterial blood $\mathrm{pCO}_{2}$. Ileus may be a clinical manifestation of splanchnic hypoperfusion; however, other causes must always be excluded. Similarly, one of the causes of acute derangement of liver transaminases may be inadequate hepatic oxygen delivery, and lack of renal blood flow may result in poor urine output and a rise in the serum urea and creatinine.

\section{PERFUSION PRESSURE}

Global perfusion pressure is measured via invasive arterial blood pressure monitoring. However, without CO measurement two erroneous inferences are possible: first, that an "adequate" blood pressure signifies an "adequate" CO; and second that manoeuvres that raise the blood pressure also result in elevation of $\mathrm{CO}$ (equation 1 ). In fact neither may be the case. The failing myocardium responds poorly to a high systemic vascular resistance; thus an increase in blood pressure may result in a fall in CO; conversely lowering the systemic vascular resistance with vasodilator therapy may produce a considerable gain in terms of CO despite a small drop in blood pressure. ${ }^{56}$

\section{OXYGEN CONSUMPTION}

Oxygen consumption can now be measured at the bedside, even in the smallest patients, the commonest ICU method being indirect calorimetry. ${ }^{26}$ Providing that oxygen delivery and perfusion pressure are adequate, an inability to consume oxygen may be inferred without direct measurement from the combination of a raised blood lactate with a high mixed venous oxygen saturation.

\section{IDENTIFYING THE SOURCE OF INADEQUATE OXYGEN DELIVERY OR EXCESSIVE CONSUMPTION Oxygen delivery}

Two of the components of oxygen delivery, haemoglobin concentration and arterial haemoglobin oxygen saturation, can be easily determined (table 1). The cause of a deficiency in the third component, $\mathrm{CO}$ is not always apparent, as this can be caused by abnormalities in heart rate, preload, contractility, afterload, or any combination of the four.

\section{Heart rate}

Heart rate is the easiest parameter to measure at the bedside. Cardiac output can be adversely affected by extreme sinus tachycardia (for example, with hypovolaemia or excessive inotrope use), bradycardia, or any arrhythmia producing loss of atrioventricular synchrony.

\section{Preload}

Preload encompasses the variety of factors resulting in ventricular end diastolic volume. It is important to appreciate that the preload of the right and left heart are not necessarily the same. The two commonly used measures of preload, namely central venous pressure (right heart) and pulmonary artery occlusion pressure (left heart) both have clinical limitations. ${ }^{57} 58$ This is because many factors affect the ability of a pressure measurement to act as a marker of volume status, including venous capacitance, cardiac chamber compliance, valve competence, pulmonary artery pressures, and the ability of the lung to function as a Starling resistor with positive pressure ventilation, to name a few. ${ }^{59}$ However it is probably reasonable to assume that a low central venous pressure may represent underfilling, and this parameter may be useful for trending. ${ }^{60}$

Two new volume based measures, intrathoracic blood volume and right ventricular end diastolic volume, have been evaluated favourably as preload indicators. ${ }^{57561}$ Both are calculated from modifications of a thermodilution technique; however, neither has been adequately evaluated in children. Analysis of variation in arterial pulse pressure waveform shows great promise, and can easily be incorporated into routine invasive blood pressure monitoring on a continuous basis. ${ }^{62}$ Several transoesophageal Doppler derived parameters have been explored ${ }^{63-65}$; one has been used successfully in adults to guide intraoperative volume replacement. ${ }^{63}$ Two echocardiographic indicators of preload have been suggested. The functional preload index requires specialised software and a series of calculations, thus limiting its clinical use, ${ }^{66}$ while interpretation of mitral inflow velocity profiles is often beset by confounding variables. ${ }^{14}$ Diastolic dysfunction also affects preload, although controversy exists regarding the interpretation of echocardiographic parameters of diastolic function in certain clinical scenarios. ${ }^{13}{ }^{14}$ 


\section{Contractility}

An adequate bedside measure of contractility does not exist. The echocardiographic stress velocity index has provided insight into pathophysiology, ${ }^{67-69}$ but requires the same technical specifications as the functional preload index. Recently one of the assumptions on which this parameter is based, namely the linear relation between stress velocity (contractility) and end systolic wall stress (afterload) has been questioned, suggesting a reappraisal of its clinical interpretation. ${ }^{70}$ Stoke work index represents the area enclosed by the ventricular pressure-volume loop; however, this may be estimated at the bedside from stroke index and arterial pressure measurements (table 1). Although not a true measure of contractility, it allows some insight into cardiac reserve, namely how stoke index (volume) is adjusted in the face of changing afterload.

\section{Afterload}

Afterload is defined as the force opposing left ventricular fibre shortening during ventricular ejection, in other words left ventricular wall stress. Wall stress can be measured at various points throughout cardiac ejection, although it is thought that calculation at end systole provides the best measure of afterload..$^{71}$ Calculation of wall stress requires measurement of end systolic transmural ventricular pressure, and echocardiographic measurement of left ventricular end systolic dimension and wall thickness. ${ }^{71}$ Here transmural pressure equals the difference between intra- and extraventricular (or intrathoracic) pressures. While intraventricular pressure can be estimated from the mean arterial pressure, ${ }^{72}$ accurate estimation of extraventricular/intrathoracic pressure is difficult and may involve measurement of oesophageal or pleural pressures. Using this approach it is easy to understand how factors that increase intrathoracic pressure, such as positive pressure ventilation, result in a reduction in afterload. A recent publication has suggested that the clinical contribution of extracardiac pressure when calculating indices of systolic function may in fact be minimal ${ }^{73}$; however, whether this is so for calculation of afterload remains to be seen.

The commonest clinical measure of afterload is systemic vascular resistance. This parameter is analogous to Ohm's law, treating the heart as a "DC" (constant) rather than an "AC" (pulsatile) generator of flow, by measuring the ratio of mean pressure drop across the systemic vascular bed to the flow (table 1). Seen in this light, the limitations of this calculation are obvious; however, it provides the clinician with a single figure that has prognostic value. ${ }^{74}$

The importance of minimising afterload in the failing myocardium is well documented. However, the clinical dilemma is usually one of balancing afterload reduction against maintaining perfusion pressure (blood pressure); in reality this can only be optimised if CO is measured.

\section{Oxygen consumption}

Many clinical situations are known to elevate oxygen consumption (fig 1). Thus where an obvious oxygen supply:demand imbalance exists, reduction in oxygen consumption may be more fruitful than attempting to elevate delivery to supranormal levels. ${ }^{75}$ Examples include maintenance of normo- or mild hypothermia following cardiac surgery, provision of adequate analgesia and sedation, initiation of mechanical ventilation to decrease work of breathing, and avoidance of excessive doses of inotropic agents, thereby minimising potential for excessive thermogenesis and myocardial oxygen consumption.

\section{SUMMARY}

Systolic cardiac function comprises four interrelated variables: heart rate, preload, contractility, and afterload, which along with diastolic cardiac properties, result in CO. Accurate analysis of the components of cardiac function at the bedside is difficult, however measurement of $\mathrm{CO}$ in paediatric practice is now feasible. Interpretation of this parameter requires both a quantitative and a qualitative approach, which in turn requires the integration of a wide array of physiological, laboratory, and clinical parameters. Cardiac output should always be considered in terms of its contribution to global oxygen delivery/consumption balance.

\section{Authors' affiliations}

S M Tibby, I A Murdoch, Department of Paediatric Intensive Care, Guy's Hospital, London SE 1 9RT, UK

\section{REFERENCES}

1 Proulx F, Gauthier M, Nadeau D, et al. Timing and predictors of death in pediatric patients with multiple organ system failure. Crit Care Med 1994;22:1025-31

2 Wilkinson JD, Pollack MM, Ruttimann UE, et al. Outcome of pediatric patients with multiple organ system failure. Crit Care Med $1986 ; 14: 271-4$

3 Shekerdemian L, Bohn D. Cardiovascular effects of mechanical ventilation. Arch Dis Child 1999;80:475-80.

4 MacKenzie SJ, Nimmo GR, Armstrong IR, et al. The haemodynamic effects of intermittent haemofiltration in critically ill patients. Intensive Care Med 1991;17:346-9.

5 Mercier JC, Beaufils F, Hartmann JF, et al. Hemodynamic patterns of meningococcal shock in children. Crit Care Med 1988;16:27-33.

6 Ceneviva G, Paschall JA, Maffei F, et al. Hemodynamic support in fluid-refractory pediatric septic shock. Pediatrics 1998;102:e19.

7 Tibby SM, Hatherill M, Marsh M, et al. Clinicians' abilities to estimate cardiac index in ventilated children and infants. Arch Dis Child 1997;77:516-18.

8 Teitel DF. Cardiac physiology. In Chang AC, Hanley FL, Wernovsky G, Wessel DL, eds. Pediatric cardiac intensive care. Philadelphia: Lippincot Williams \& Wilkins, 1998:25-9

9 Little WC, Cheng CP, Mumma M, et al. Comparison of measures of left ventricular contractile performance derived from pressure-volume loops in conscious dogs. Circulation 1989:80:1378-87.

10 Glower DD, Spratt JA, Snow ND, et al. Linearity of the Frank-Starling relationship in the intact heart: the concept of preload recruitable stroke work. Circulation 1985;71:994-1009.

11 Dougherty AH, Naccarelli GV, Gray EL, et al. Congestive heart failure with normal systolic function. Am J Cardiol 1984;54:778-82.

12 Glantz SA, Parmley WW. Factors which affect the diastolic pressure-volume curve. Circ Res 1978;42:171-80.

13 Courtois M, Ludbrook PA, Kovacs SJ. Unsolved problems in diastole. Cardiol Clin 2000;18:653-67.

14 Appleton CP, Hatle LK, Popp RL. Relation of transmitral flow velocity patterns to left ventricular diastolic function: new insights from a combined hemodynamic and Doppler echocardiographic study. J Am Coll Cardiol 1988;12:426-40.

15 Wernovsky G, Wypij D, Jonas RA, et al. Postoperative course and hemodynamic profile after the arterial switch operation in neonates and infants. A comparison of low-flow cardiopulmonary bypass and circulatory arrest. Circulation 1995;92:2226-35.

16 Iberti TJ, Fischer EP, Leibowitz AB, et al. A multicenter study of physicians' knowledge of the pulmonary artery catheter. JAMA 1990;264:2928-32.

17 Gnaegi A, Feihl F, Perret C. Intensive care physicians' insufficient knowledge of right-heart catheterization at the bedside: time to act? Crit Care Med 1997;25:213-20

18 Thompson AE. Pulmonary artery catheterization in children. New Horiz 1997:5:244-50.

19 Shephard JN, Brecker SJ, Evans TW. Bedside assessment of myocardia performance in the critically ill. Intensive Care Med 1994;20:513-21.

20 Perloff WH. Invasive measurements in the PICU. In: Fuhrman BP, Zimmerman JJ, eds. Pediatric critical care, 2nd edn. St Louis: Mosby, 1998:70-86

21 Fanconi S, Burger R. Measurement of cardiac output in children. Intensive Care World 1992;9:8-12.

22 Tibby SM, Brock G, Marsh M, et al. Haemodynamic monitoring in critically ill children. Care Crit Ill 1997;13:86-9.

23 Marik PE. Pulmonary artery catheterization and esophageal Doppler monitoring in the ICU. Chest 1999;116:1085-91.

24 Tibby SM, Murdoch IA. Measurement of cardiac output and tissue perfusion. Curr Opin Crit Care 2002;14:303-9

25 Arnold JH, Stenz RI, Thompson JE, et al. Noninvasive determination of cardiac output using single breath $\mathrm{CO} 2$ analysis. Crit Care Med 1996;24:1701-5

26 Weyland $W$, Weyland $A$, Fritz $U$, et al. A new paediatric metabolic monitor. Intensive Care Med 1994;20:51-7.

27 Behrends $M$, Kernbach M, Braver A, et al. In vitro validation of a metabolic monitor for gas exchange measurements in ventilated neonates. Intensive Care Med 2001;27:228-35

28 Meier P, Zierler KL. On the theory of the indicator dilution method for measurement of blood flow and volume J Appl Physiol 1954;6:73 1-44.

29 Weyland A, Buhre W, Hoeft A, et al. Application of a transpulmonary double indicator dilution method for postoperative assessment of cardiac index, pulmonary vascular resistance index, and extravascular lung water 
in children undergoing total cavo-pulmonary anastomosis: preliminary results in six patients. J Cardiothorac Vasc Anesth 1994;8:636-41.

30 Linton RA, Band DM, Haire KM. A new method of measuring cardiac output in man using lithium dilution. Br J Anaesth 1993;71:262-6.

31 Linton RA, Jonas MM, Tibby SM, et al. Cardiac output measured by lithium dilution and transpulmonary thermodilution in patients in a paediatric intensive care unit. Intensive Care Med 2000;26:1507-11

32 Tibby SM, Hatherill M, Murdoch IA. Use of transesophageal Doppler ultrasonography in ventilated pediatric patients: derivation of cardiac output. Crit Care Med 2000;28:2045-50.

33 Colan SD. Principles of echocardiography. In: Chang AC, Hanley FL, Wernovsky G, Wessel DL, eds. Pediatric cardiac intensive care. Philadelphia: Lippincott Williams \& Wilkins, 1998:425-39.

34 Aldousany A, Marcu B. Perioperative echocardiographic examination in the intensive care setting. In: Chang AC, Hanley FL, Wernovsky G, Wessel DL, eds. Pediatric cardiac intensive care. Philadelphia: Lippincott Williams \& Wilkins, 1998:440-6

35 Baan J, van der Velde ET, de Bruin HG, et al. Continuous measurement of left ventricular volume in animals and humans by conductance catheter. Circulation 1984;70:812-23.

36 Antonini $M$, Meloncelli S, Dantimi C, et al. Haemodynamic study by $\mathrm{PiCCO}$ system with brachial artery access during anesthesia for abdominal aortic aneurysm repair. Minerva Anestesio 2001;67:447-56.

37 Jansen JR, Schreuder JJ, Mulier JP, et al. A comparison of cardiac output derived from the arterial pressure wave against thermodilution in cardiac surgery patients. BrJ Anaesth 2001;87:212-22.

38 Linton NW, Linton RA. Estimation of changes in cardiac output from the arterial blood pressure waveform in the upper limb. Br J Anaesth 2001;86:486-96.

39 Subramanian S, Kellum JA. The meaning of lactate. In: Vincent J-L, ed. Yearbook of intensive care and emergency medicine. Berlin: Springer-Verlag, 2000:743-51.

40 Hatherill M, Mclntyre AG, Wattie M, et al. Early hyperlactataemia in critically ill children. Intensive Care Med 2000;26:314-18.

41 Hatherill $M$, Saijanhar T, Tibby SM, et al. Serum lactate as a predictor of mortality after paediatric cardiac surgery. Arch Dis Child 1997;77:235-8

42 Munoz R, Laussen PC, Palacio G, et al. Changes in whole blood lactate levels during cardiopulmonary bypass for surgery for congenital cardiac disease: an early indicator of morbidity and mortality. J Thorac Cardiovasc Surg 2000;119:155-62.

43 Whyte RK. Mixed venous oxygen saturation in the newborn. Can we and should we measure it? Scand J Clin Lab Invest 1990;50(supp 203):203-11.

44 Rivers EP, Ander DS, Powell D. Central venous oxygen saturation monitoring in the critically ill patient. Curr Opin Crit Care 2001;7:204-11

45 Salim MA, DiSessa TG, Arheart KL, et al. Contribution of superior vena caval flow to total cardiac output in children. A Doppler echocardiographic study. Circulation 1995;92:1860-5

46 Buheitel G, Scharf J, Hofbeck M, et al. Estimation of cardiac index by means of the arterial and the mixed venous oxygen content and pulmonary oxygen uptake determination in the early post-operative period following surgery of congenital heart disease. Intensive Care Med 1994;20:500-3

47 Charpie JR, Dekeon MK, Goldberg CS, et al. Postoperative hemodynamics after Norwood palliation for hypoplastic left heart syndrome. Am J Cardiol 2001;87:198-202.

48 Duke T, Butt W, South $M$, et al. The DCO2 measured by gastric tonometry predicts survival in children receiving extracorporeal life support. Comparison with other hemodynamic and biochemical information. Chest 1997;111:174-9.

49 Hamilton-Davies C, Mythen MG, Salmon JB, et al. Comparison of commonly used clinical indicators of hypovolaemia with gastrointestinal tonometry. Intensive Care Med 1997;23:276-81

50 Saavedra JM, Harris GD, Li S, et al. Capillary refilling (skin turgor) in the assessment of dehydration. Am J Dis Child 1991;145:296-8.

51 Hoelzer DJ, Brian MB, Balsara VJ, et al. Selection and nonoperative management of pediatric blunt trauma patients: the role of quantitative crystalloid resuscitation and abdominal ultrasonography. J Trauma 1986;26:57-62

52 Tibby SM, Hatherill M, Murdoch IA. Capillary refill and core-peripheral temperature gap as indicators of haemodynamic status in paediatric intensive care patients. Arch Dis Child 1999:80:163-6.

53 Butt W, Shann F. Core-peripheral temperature gradient does not predict cardiac output or systemic vascular resistance in children. Anaesth Intensive Care 1991;19:84-7.

54 Kolkman JJ, Otte JA, Groeneveld AB. Gastrointestinal luminal PCO2 tonometry: an update on physiology, methodology and clinical applications. Br J Anaesth 2000;84:74-86.

55 Thorburn K, Hatherill M, Roberts PC, et al. Evaluation of the 5-French saline paediatric gastric tonometer. Intensive Care Med 2000;26:973-80.

56 Colan SD. Utility and feasibility of assessing myocardial mechanics after bypass. Crit Care Med 1998;26:822-4.

57 Lichtwarck-Aschoff $M$, Beale R, Pfeiffer UJ. Central venous pressure, pulmonary artery occlusion pressure, intrathoracic blood volume, and right ventricular end-diastolic volume as indicators of cardiac preload. Crit Care 1996;11:180-8

58 Wiesenack C, Prasser C, Keyl C, Rodig G. Assessment of intrathoracic blood volume as an indicator of cardiac preload: single transpulmonary thermodilution technique versus assessment of pressure preload parameters derived from a pulmonary artery catheter. J Cardiothorac Vasc Anesth $2001 ; 15: 584-8$.

59 O'Quin R, Marini JJ. Pulmonary artery occlusion pressure: clinical physiology, measurement, and interpretation. Am Rev Respir Dis 1983;128:319-26.

60 Skinner JR, Milligan DW, Hunter $\mathrm{S}$, et al. Central venous pressure in the ventilated neonate. Arch Dis Child 1992;67:374-7.

61 Safcsak K, Nelson LD. Right heart volumetric monitoring: measuring preload in the critically injured patient. AACN Clin Issues $1999 ; 10: 22-31$.

62 Michard F, Boussat $S$, Chemla D, et al. Relation between respiratory changes in arterial pulse pressure and fluid responsiveness in septic patients with acute circulatory failure. Am J Respir Crit Care Med 2000;162:134-8

63 Sinclair S, James S, Singer M. Intraoperative intravascular volume optimisation and length of hospital stay after repair of proximal femoral fracture: randomised controlled trial. BMV 1997:315:909-12.

64 Feissel M, Michard F, Mangin I, et al. Respiratory changes in aortic blood velocity as an indicator of fluid responsiveness in ventilated patients with septic shock. Chest 2001;119:867-73

65 Tibby SM, Hatherill M, Durward A, et al. Are transoesophageal Dopple parameters a reliable guide to paediatric haemodynamic status and fluid management? Intensive Care Med 2001;27:201-5.

66 Colan SD, Trowitzsch E, Wernovsky G, et al. Myocardial performance after arterial switch operation for transposition of the great arteries with intact ventricular septum. Circulation 1988;78:132-41.

67 Colan SD, Borow KM, Neumann A. Left ventricular end-systolic wall stress-velocity of fiber shortening relation: a load-independent index of myocardial contractility. J Am Coll Cardiol 1984;4:715-24.

68 Feltes TF, Pignatelli R, Kleinert S, et al. Quantitated left ventricular systolic mechanics in children with septic shock utilizing noninvasive wall-stress analysis. Crit Care Med 1994;22:1647-58.

69 Bryant RM, Shirley RL, Ott DA, et al. Left ventricular performance following the arterial switch operation: use of noninvasive wall stress analysis in the postoperative period. Crit Care Med 1998;26:926-32

70 Baneriee A, Brook MM, Klautz RJ, et al. Nonlinearity of the left ventricular end-systolic wall stress-velocity of fiber shortening relation in young pigs: a potential pitfall in its use as a single-beat index of contractility. J Am Coll Cardiol 1994;23:514-24.

71 Lang RM, Borow KM, Neumann A, et al. Systemic vascular resistance an unreliable index of left ventricular afterload. Circulation 1986;74:1114-23

72 Rowland DG, Gutgesell HP. Use of mean arterial pressure for noninvasive determination of left ventricular end-systolic wall stress in infants and children. Am J Cardiol 1994;74:98-9.

73 Haney MF, Johansson G, Haggmark S, et al. Analysis of left ventricular systolic function during elevated external cardiac pressures: an examination of measured transmural left ventricular pressure during pressure-volume analysis. Acta Anaesthesiol Scand 2001;45:868-74.

74 Groeneveld AB, Nauta JJ, Thijs LG. Peripheral vascular resistance in septic shock: its relation to outcome. Intensive Care Med 1988; 14:141-7.

75 Hayes MA, Timmins AC, Yau EH, et al. Elevation of systemic oxygen delivery in the treatment of critically ill patients. N Engl J Med 1994; 330: 1717-22.

76 Shann F. Drug doses, 8th edn. Melbourne: Collective Pty Ltd, 1994:61

77 Wippermann CF, Huth RG, Schmidt FX, et al. Continuous measurement of cardiac output by the Fick principle in infants and children: comparison with the thermodilution method. Intensive Care Med 1996;22:467-71

78 Hillis LD, Firth BG, Winniford MD. Analysis of factors affecting the variability of Fick versus indicator dilution measurements of cardiac output. Am J Cardiol 1985;56:764-8.

79 Medin DL, Brown DT, Wesley R, et al. Validation of continuous thermodilution cardiac output in critically ill patients with analysis of systematic errors. J Crit Care 1998;13:184-9.

80 Nishikawa T, Dohi S. Errors in the measurement of cardiac output by thermodilution. Can J Anaesth 1993;40:142-53.

81 Smith-Wright DL, Green TP, Lock JE, et al. Complications of vascular catheterization in critically ill children. Crit Care Med 1984;12:101517 .

82 Tibby SM, Hatherill M, Marsh M, et al. Clinical validation of cardiac output using femoral artery thermodilution with direct Fick in ventilated children and infants. Intensive Care Med 1997;23:987-91.

83 Stern H, Haberhauer P, Emmrich P, et al. Interobserver and spontaneous variability of Doppler echocardiography measured cardiac output in children with congenital heart defects. Z Kardiol 1990;79:89-95.

84 Claflin KS, Alverson DC, Pathak D, et al. Cardiac output determinations in the newborn. Reproducibility of the pulsed Doppler velocity measurement. J Ultrasound Med 1988;7:311-15.

85 Tibballs J, Hochmann M, Osborne A, et al. Accuracy of the BoMED NCCOM3 bioimpedance cardiac output monitor during induced hypotension: an experimental study in dogs. Anaesth Intensive Care 1992;20:326-3 